\title{
Perceptions Towards Diagnosis Of Prostate Cancer in Tharaka Nithi County, Kenya
}

\author{
Timothy Kinoti Kirungia ${ }^{1}$, Consolata Kirigia ${ }^{2 *}$, Lucy Gitonga ${ }^{3}$, Silas Kiruki ${ }^{3}$ \\ ${ }^{I}$ Department of Nursing, Kenya Medical Training College, Chuka, Kenya. \\ ${ }^{2}$ School of Nursing, University of Embu, Embu, Kenya \\ ${ }^{3}$ Chuka University, Chuka, Kenya \\ Corresponding author: consolatakirigia@gmail.com
}

\begin{abstract}
Background: Cancers are leading cause of death in developed nations and the second leading cause of death in developing nations. One of the most frequently diagnosed cancers among men is Prostate cancer (PCa).

Purpose: This research study aimed at exploring the patient's and family's perceptions towards diagnosis of prostate cancer in Tharaka Nithi County, Kenya.

Methods: The study population comprised of families and PCa patients attending Chogoria mission hospital, Magutuni sub-county hospital, Chuka county hospital and Tharaka subcounty hospital which were selected purposefully, from which a sample of 70 patients and 65 family members was obtained. Purposive sampling method was used to sample patients and families. Data were collected using interview schedules and focus group discussions and summarized using descriptive statistics. Statistical analysis for association between variables was done using chi-square tests.

Results: The study revealed that; men in the age group 60-70 were most prone to the development of prostate cancer. A high percentage of patients and families perceived that prostate cancer was caused by genetic factors and should be treated by medical personnel. Over $50 \%$ of the patients and families had no idea of the symptoms of prostate cancer neither had they heard of it before the patient was diagnosed. The study also revealed that $50 \%$ of the patients suffered hypertension, $80 \%$ did not believe the diagnosis at first and over $50 \%$ perceived the diagnosis as a death sentence. PCa patients showed the highest level of acceptance and lung cancer patients the poorest acceptance of illness. Over $90 \%$ of the patients and families observed general health improvement after medication. Over $78 \%$ of the patients and familyes had embraced insurance as a way of meeting the medical expenses. Conclusion: This study demonstrated that patients and families perceived the diagnosis of prostate cancer as a death sentence. They also had low level of knowledge about PCa. A strong correlation was demonstrated between family history and increased risk of PCa. However, it was demonstrated that family history of PCa did not increase levels of knowledge on the causes of PCa.
\end{abstract}

Keywords: Perceptions, Diagnosis, Prostate Cancer, Outcomes, Patients, Family’s. 
Journal Of Nursing Practice

http://thejnp.org

ISSN: 2614-3488 (print); 2614-3496 (online)

Vol.4 No.2. April 2021. Page.154-166

\section{BACKGROUND}

Prostate cancer is the leading cancer in both occurrence and the number of deaths in Africa though African men suffer disproportionately from prostate cancer as compared to men from other parts of the world (Rebbeck et al, 2011). Cancers are the leading cause of deaths in developed countries and the second leading cause of death in developing countries with the leading cause of death being cardiovascular diseases (Calys-Tagoe et al, 2014). In 2012, 14.1 million new cancer cases were recorded globally with 8.2 million deaths and 32.6 million still living with the disease (Calys-Tagoe et al., 2014). The ministry of health estimates that by 2030 , out of the cancer cases reported globally, $70 \%$ will come from developing countries. Breast cancer that predominantly affects women and lung cancer that is mostly diagnosed in males are the two commonly cancers that are diagnosed and the two are leading in causation of global cancer-related deaths (Calys-Tagoe et al., 2014). However, according to Etawo et al (2012), the second most frequently diagnosed cancer among men is prostate cancer $(\mathrm{PCa})$. Cancer of the prostate is a disease pathway whereby prostate gland cells proliferate abnormally, ignoring growth-regulating signals in the environment surrounding the cells (Wolf, 2013).

The burden of $\mathrm{PCa}$ is projected to grow to approximately 1.7 million new cases by 2030 simply due to the growth and aging of the worlde's population (Jemal et al, 2012). According to Roth et al (2008) PCa is the most prevalent type of cancer among males in the United States with an estimated 218,000 new cases of prostate cancer being diagnosed and 27,000 patients succumbing from the ailment every year. Moreover, approximately one in every five American men is affected by the disease (Roth et al., 2008). Statement of the problem the burden of prostate cancer has significantly increased in the last two decades. The financial, social and emotional devastation that often accompanies a diagnosis of prostate cancer is in large part due to the perceptions surrounding the disease and these perceptions need to be urgently addressed. Many individuals associate the diagnosis of any cancer with death, and they perceive cancer as a punishment from God. This study aimed at exploring the patient's and family's perceptions towards diagnosis of prostate cancer in the County of Tharaka Nithi.

\section{OBJECTIVE}

The main objective of this study was to determine the patient's and family's perceptions towards diagnosis of prostate cancer in Tharaka Nithi County, Kenya.

Ho: History of Prostate Cancer in the family and the Knowledge level on Prostate Cancer causes are Independent.

\section{METHODS}

Study area

This study was conducted in Tharaka Nithi County. The county has three major hospitals (Chuka level four hospital, Magutuni sub-county hospital and Tharaka sub- county hospital) and one referral mission hospital (Chogoria Mission Hospital) where patients diagnosed with prostate are followed. The four hospitals acted as strata. Chogoria mission hospital is located in Mwimbi sub-county, approximately one kilometer from the Nairobi Meru highway. It has a bed capacity of 250 patients and it has a fully functional palliative clinic. Chuka level four hospitals is located in Chuka town and it has a bed capacity of approximately 100 patients. The hospital is the largest county hospital in Tharaka Nithi County. Magutuni sub-county hospital is located in Mwimbi sub-county and it has a bed capacity of 83 patients. Tharaka sub- county hospital is located in Tharaka south sub-county and it has a bed capacity of 70 patients. 


\section{Journal Of Nursing Practice}

Design

The study design was descriptive cross-sectional, which enabled the researcher to determine the patients and family's perceptions towards diagnosis of prostate cancer. The design was suitable because of the qualitative nature of this study. Moreover, this research study was a social science type of research and thereby study questions needed descriptive answers in order to be answered.

\section{Population}

The target population comprised of patient's diagnosed of prostate cancer within Tharaka Nithi County. Also, one family member of all the prostate cancer patients within Tharaka Nithi County. A review of the records in the four purposively selected hospitals showed the accessible population was as follows;

Table 1: Number of patients attended to in one month.

\begin{tabular}{lc}
\hline Hospital No. of PCa patients attended to in one month \\
\hline PCEA Chogoria mission hospital & 51 \\
Magutuni sub-county hospital & 32 \\
Chuka county referral hospital & 37 \\
Tharaka sub-county hospital & 30 \\
Total & 150
\end{tabular}

Source: Hospital records (2018)

One family members of each prostate cancer patient, who were purposefully selected, comprised of the family ${ }^{\text {ee }}$ s population.

\section{Sampling}

On the other hand, sampling refers to the process used by the researcher to identify and select a group of observations or individuals for the research study in a way that the selected individuals represent the population from which they were selected. The sample size was determined using fisheres formula (fisher et al., 1998) asfollows

$$
\frac{n=Z^{2}(1-p)}{d^{2}}
$$

Where

$\mathrm{n}=$ represents the desired sample size (if the target population is greater than 10,000)

$\mathrm{Z}=$ represents a corresponding confidence level value (i.e. 1.96 for $95 \%$ confidence)

$\mathrm{d}=$ is the margin error (i.e. $0.05=5 \%$

$\mathrm{P}$ is the value estimated for the proportion of a sample that has the condition of interest (no reasonable estimate a default of $50 \%$ or 0.5 is used).

$1.96^{2} 0.5(1-0.5)$

$n=$

$$
0.05^{2}
$$

$\mathrm{n}=384.16$

$\mathrm{n}=384$ 


\section{Journal Of Nursing Practice}

http://thejnp.org

ISSN: 2614-3488 (print); 2614-3496 (online)

Vol.4 No.2. April 2021. Page.154-166

Since the target population is less than 10,000 , the sample size was adjusted using the Yamane formula, (1967) with a sample of 150 as seen on the monthly number.

$$
n f=\frac{n}{1}+\left(\frac{n}{N}\right.
$$

Where,

$\mathrm{Nf}=$ desired sample

$\mathrm{n}=$ Calculated sample

$\mathrm{N}=$ Estimate of population of study

Hence $n f=\frac{384}{1}+\left(\frac{384}{150}\right)$

$n f=107.8651685$

$n f=108$

\section{Sampling Procedure}

The researcher used purposive sampling method. The researcher went to the four purposively selected hospitals (Chogoria mission hospital, Chuka level four hospital, Magutuni sub-county hospital and Tharaka sub-county hospital) and identified patients diagnosed with prostate cancer and interviewed them. This method was applicable in this study because of the sensitivity of the information required, the qualitative nature of the information and the fact that respondents are men whose problem is a very sensitive organ. For the families, the patient purposefully referred the researcher to the appropriate family member who was also interviewed. However, during data collection there were five patients who came to the hospital alone and therefore the number of patients exceeded that of families by five.

\section{Eligibility Criteria}

Eligibility criteria depends on the characteristics that are mandatory to the repondentd in order to be included in the study research. Patients included to the sample were prostate cancer patients aged 18 years and above, and those who were willing to participate. Those excluded were patients diagnosed of prostate cancer but not willing to participate in the study. Families ${ }^{\text {ee }}$ included in the study were families with a prostate cancer patient and those who were willing to participate.

\section{Data Collection Procedure}

This is the step by step process of acquiring data on the variables of study in a coordinated manner to enable answering of research questions by the researcher. Data collection was performed by the researcher and one research assistant for a period of two months in the months of March and April, 2019. During this period,

the researcher and the research assistant spent one month in each hospital where the required number of patients and families were interviewed.

\section{Data Collection Instruments}

Data collection was carried out by the researcher and an assistant using interview schedules and focus group discussions. The interview schedules comprised of four sections. Section A gathered social demographic data, section $\mathrm{B}$ gathered data on knowledge, section $\mathrm{C}$ gathered data on the outcome of prostate cancer diagnosis and section $\mathrm{D}$ gathered data on health seeking behaviour. There was an interview schedule for the patients and another one for the families. 
Journal Of Nursing Practice

http://thejnp.org

ISSN: 2614-3488 (print); 2614-3496 (online)

Vol.4 No.2. April 2021. Page.154-166

Pre-testing

Pre-testing was done and enabled the researcher determine practicability and feasibility of the selected research design. Pre-testing is the process of trying out techniques for research and practically of methods to establish their applicability and if necessary, make appropriate adjustments. Pre-testing was done at Embu teaching and Referral hospital in Embu county where 10 prostate cancer patients attending the palliative clinic and ten families were interviewed. This ensured reliability and sustainability of the interview schedule. Findings from the pre-test helped inform the final interview schedule.

\section{Data Analysis and Presentation}

In order to explain and describe the information in terms that were meaningful, it was subjected to treatment statistically. The quantitative infromation was entered into computer and analyzed for significance at $\mathrm{p}<0.05$ using Statistical Package for Social Sciences (SPSS) (version 23.0). Frequencies, percentages and mean were used. Chi-square test was used for significant association between variables. Pie charts and tables was used for data presentations.

\section{Ethical Considerations}

The researcher sought permission to carry out this research study from National Commission for Science, Technology and Innovation (NACOSTI) through the Chuka University Ethics and Research Committee for review and approval. Approval was also sought from director clinical services from Chogoria mission hospital and Tharaka Nithi County director of medical services for Magutuni sub- county hospital, Chuka county hospital and Tharaka sub-county hospital. Respondents were informed to fill an informed consent form as a proof of their acceptance and availability to participate in this research study. After the consent was obtained, the researcher informed the respondents that participation was voluntary, they were free to express their dissatisfaction anytime and they could withdraw from the research study when felt to do so. This was done to ensure that the information obtained was credible. Confidentiality of the participants was assured by asking them to maintain their anonymity by telling them not to write their name on the interview schedules

\section{RESULTS}

\section{Patients' Social Demographic Information}

This research study showed that patient's social-demographic characteristics have a role in patients and families perceptions towards diagnosis of prostate cancer.

Results from this study revealed that age group of 60-70 years is most prone to prostate cancer (30) followed by 70-80 at (23) and 50-60 at (7). The age group of 80-90 had (6), above 90 had (3) and 30-40 had (1).

The results in this study showed that the highest number of prostate cancer patients were the married people at $(82.29 \%)$ followed by widowed $(7.14 \%)$, single $(4.29 \%)$ separated $(2.86 \%)$ and those who were divorced at $(1.43 \%)$ as shown in table two. The results show that majority $(35.17 \%)$ of the patients had attained secondary education followed by primary $(31.43 \%)$, tertiary $(20 \%)$ and those of have never schooled $(12.86 \%)$. The results show that all the prostate cancer patients in this study were Christians (100\%). This is because Tharaka Nithi County is predominantly inhabited by Christians who practice Christianity. Majority $(41.23 \%)$ of the patients were being taken care by their wives followed by those cared by their daughters $(27.14 \%)$, sons $(25.71 \%)$ and lastly by brothers $(5.71 \%)$. This is shown in table two. More patients were in informal employment (74.29\%) as compared to those in formal employment $(25.71 \%)$ as shown in table two. Most of the patients had no history of 


\section{Journal Of Nursing Practice}

prostate cancer in the family $(74.29 \%)$ as compared to those who had history of prostate cancer in the family $(25.71 \%)$. (Table 2 )

Table 2: Patients ${ }^{\text {ee }}$ Social demographic information

\begin{tabular}{|c|c|c|c|c|c|c|}
\hline Variable & & Value & Frequency & & Perc & \\
\hline Marital status & & Divorced & & 1 & 1.43 & \\
\hline & & Married & 59 & & 84.29 & \\
\hline & & Separated & & 2 & 2.86 & \\
\hline & & Single & & 3 & 4.29 & \\
\hline & & Widowed & & 5 & 7.14 & \\
\hline Occupation & & Formal & 18 & & 25.71 & \\
\hline & & Informal & 52 & & 74.29 & \\
\hline Education & & None & & 9 & 12.86 & \\
\hline & & Primary & 22 & & 31.43 & \\
\hline & & Secondary & 25 & & 35.71 & \\
\hline & & Tertiary & 14 & & & 20 \\
\hline Religion & & Christian & 70 & & & 100 \\
\hline History of prostate & the & No & 52 & & 74.29 & \\
\hline family & & Yes & 18 & & 25.71 & \\
\hline Person who takes care & the & Brother & & 4 & 5.71 & \\
\hline respondent & & Daughter & 19 & & 27.14 & \\
\hline & & Son & 18 & & 25.71 & \\
\hline & & Wife & 29 & & 41.43 & \\
\hline
\end{tabular}

Body Mass Index (BMI)

The results revealed that majority of the prostate cancer patients in this study had a body mass index of between $(20-25) \mathrm{kg} / \mathrm{m} 2$ at (40) followed by a BMI of 25-30 at (13), 15-20 (10), 10-15 (6) and 35-40 (1)

\section{Co-morbidity}

The results show that majority of the patients suffered from hypertension (50\%) followed by none $(28.57 \%)$, diabetes mellitus $(8.57 \%)$, others $(7.14 \%)$ and HIV/AIDS $(5.71 \%)$ as shown in the table 3.

Table 3: Co-morbidity

\begin{tabular}{llll}
\hline Variable & Value & Frequency & Percentage \\
\hline Other illness of the respondent & Diabetes mellitus & 6 & 8.57 \\
& HIV/aids & 4 & 5.71 \\
& Hypertension & 35 & 50 \\
& None & 20 & 28.57 \\
& Others & 5 & 7.14 \\
Total & & 70 & 100 \\
\hline
\end{tabular}

Variable analysis

The results show that the patients had an average number of 5 children and average weight, height and BMI of $63.3 \mathrm{~kg}, 169.11 \mathrm{~cm}$ and 22.29 respectively as shown in Table 4. 


\section{Journal Of Nursing Practice}

http://thejnp.org

ISSN: 2614-3488 (print); 2614-3496 (online)

Vol.4 No.2. April 2021. Page.154-166

Table 4: Variable analysis for prostate cancer patients

\begin{tabular}{llllll}
\hline Variable & Mean & $\begin{array}{l}\text { Standard } \\
\text { Deviatio } \\
\mathrm{n}\end{array}$ & Median & $\begin{array}{l}\text { Lower } \\
(95 \% \mathrm{CI})\end{array}$ & $\begin{array}{l}\text { Upper(95 } \\
\% \mathrm{CI})\end{array}$ \\
\hline Age & 69.76 & 9.47 & 69.5 & 67.54 & 71.98 \\
Children & 5.17 & 2.04 & 5 & 4.69 & 5.65 \\
Duration & 2.79 & 1.86 & 2 & 2.35 & 3.22 \\
Weight & 63.3 & 12.81 & 61 & 60.3 & 66.3 \\
Height & 169.11 & 11.63 & 168 & 166.38 & 171.83 \\
BMI & 22.29 & 3.99 & 22.48 & 21.36 & 23.23 \\
\hline
\end{tabular}

Patients' Knowledge in regard to Prostate Cancer

This study sought to investigate the patients "e knowledge level towards prostate cancer because knowledge influences the perceptions.

Causes of Prostate Cancer

Majority of the patients responded that prostate cancer is caused by genetics $(60 \%)$ followed by witchcraft $(21.43 \%)$, curse $(8.57 \%)$, others $(7.14 \%)$ and demons $(2.18 \%)$ as shown in the figure 4.

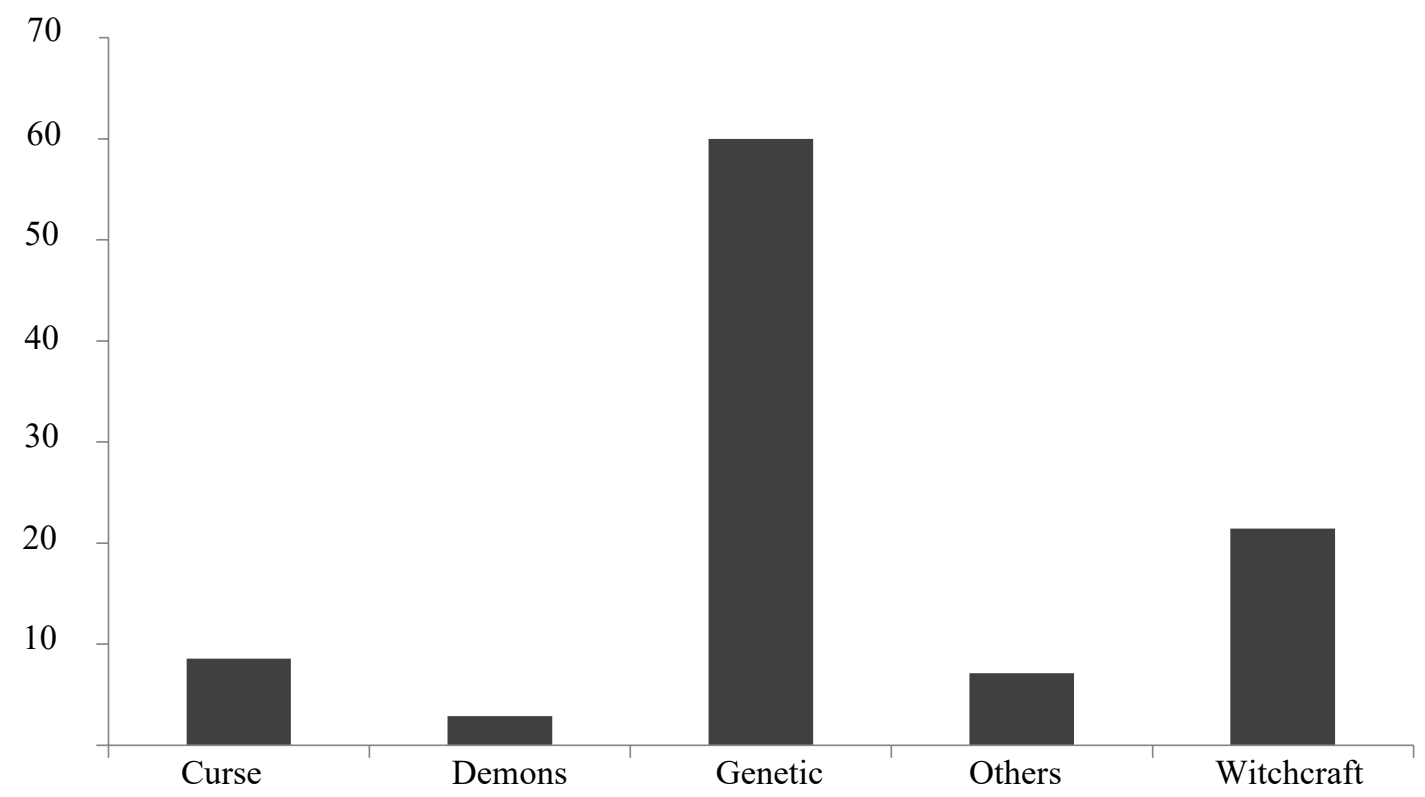

Figure 4: Patients ${ }^{\text {ee }}$ knowledge on the causes of prostate cancer

People who should treat Patients

Most of the patients responded that prostate cancer patients should be treated by medical personnel $(75.71 \%)$ followed by religious people $(21.43 \%)$, herbal practitioners $(1.43 \%)$ and witchdoctors $(1.43 \%)$ as shown in the Figure 5 


\section{Journal Of Nursing Practice}

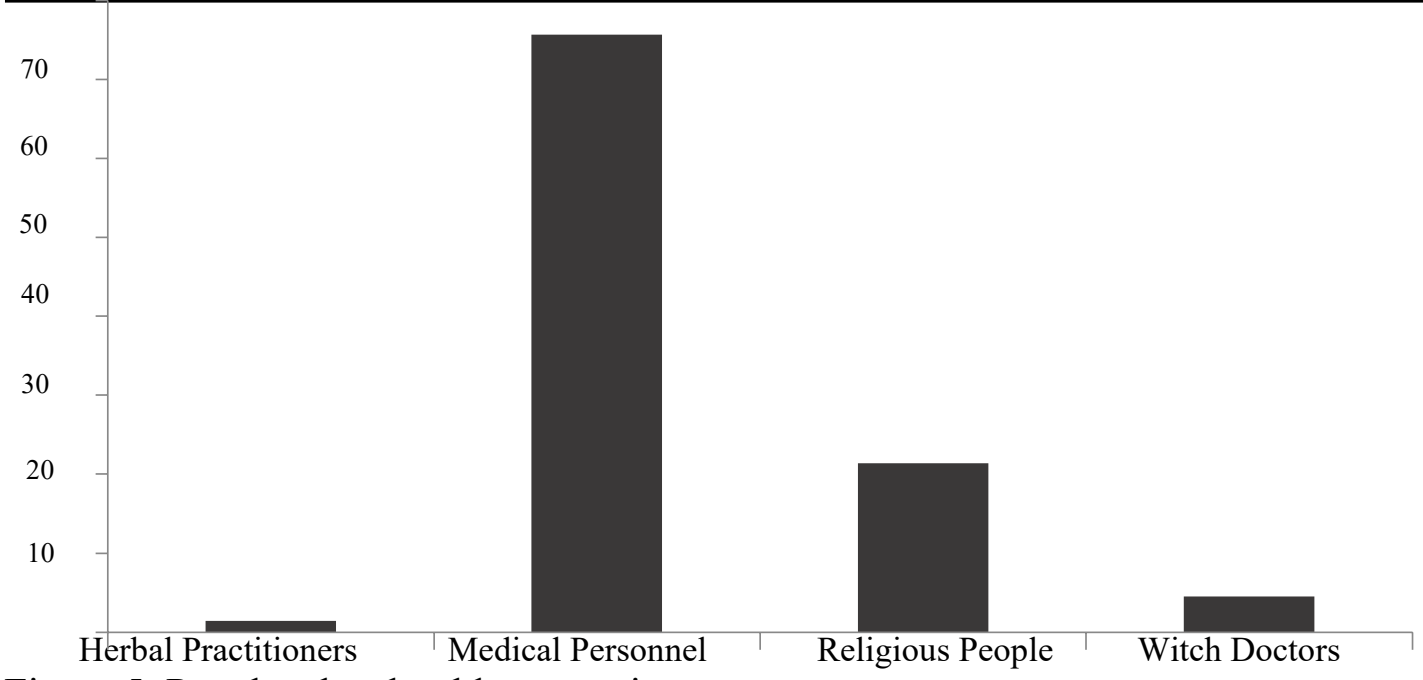

Figure 5: People who should treat patients

\section{Knowledge on Prostate Cancer symptoms}

The patients were asked if they knew the symptoms of prostate cancer and majority of them didn't (55.7\%). Those who knew the symptoms were the minority at (44.3\%). Moreover, when asked to mention the symptoms, majority indicated difficult in urinate

\section{Association between Education level and Knowledge on Prostate Cancer}

For the family's education level versus knowledge on prostate cancer, the hypothesis tested was;

H0: Families Education level and knowledge on prostate cancer are independent. H1: There is an association between family's education level and knowledge on prostate cancer. From the analysis X2(3) $=28.539, p$ value $\leq 0.001$, (table 5). Since $p$ value was less than level of significance, the null hypothesis (that education level of a family and knowledge on prostate cancer were independent) was rejected. The test showed

that there was an association between families education level and the much they knew about prostate cancer. For the patient's education level versus knowledge on prostate cancer, the hypothesis tested was; H0: Patient's Education level and Knowledge on prostate cancer are independent. H1: There is an association between Patient's Education and knowledge on prostate cancer. From the results, X2(3) $=10.469, p$ value $\leq 0.001$ (table 6). Since p value was less than the level of significance, the null hypothesis (that education level of a prostate cancer patient and knowledge on prostate cancer were independent) was rejected. The test showed that there is association between education level of a prostate cancer patient and knowledge on prostate cancer.

Table 5: Chi-square test for family ${ }^{\text {ee }}$ s education level and knowledge on prostate cancer

\begin{tabular}{llll}
\hline & Value & df & Asymp. Sig. (2-sided) \\
\hline Pearson Chi-Square & $28.539^{\mathrm{a}}$ & 3 & .000 \\
Likelihood Ratio & 31.464 & 3 & .000 \\
Linear-by-Linear & 25.121 & 1 & .000 \\
Association & & & \\
N of Valid Cases & 65 & & \\
\hline
\end{tabular}




\section{Journal Of Nursing Practice}

http://thejnp.org

ISSN: 2614-3488 (print); 2614-3496 (online)

Vol.4 No.2. April 2021. Page.154-166

Table 6: Chi-square test for patient ${ }^{e c}$ s education level and knowledge on prostate cancer

\begin{tabular}{llll}
\hline & Value & df & Asymp. Sig. (2-sided) \\
\hline Pearson Chi-Square & $10.469^{\mathrm{a}}$ & 3 & .015 \\
Likelihood Ratio & 10.698 & 3 & .013 \\
Linear-by-Linear & 7.560 & 1 & .006 \\
Association & & & \\
N of Valid Cases & 70 & & \\
\hline
\end{tabular}

Families Perceived Outcome following Prostate Cancer diagnosis of a relative The results show that majority of the families did not believe the diagnosis $(90.77 \%)$ and the minority did believe the results $(9.23 \%)$ as show in Table 11 .

Table 11: Believing of diagnosis results

\begin{tabular}{|c|c|c|c|}
\hline Variable & Value & Frequency & Percentage \\
\hline Believing of the & Yes & 59 & 90.77 \\
\hline diagnosis & No & 6 & 9.23 \\
\hline Total & & 65 & 100 \\
\hline
\end{tabular}

Meaning of Prostate Cancer diagnosis

Majority of the families responded that positive diagnosis of their relative meant disease burden $(84.62 \%)$ followed by normal life $(13.85 \%)$ and loss of work $(1.54 \%)$ as shown in Table 12.

Table 12: Meaning of Prostate Cancer diagnosis

\begin{tabular}{|l|l|l|}
\hline Variable & Frequency & Percentage \\
\hline $\begin{array}{l}\text { Meaning of prostate } \\
\text { cancer diagnosis of the } \\
\text { relative }\end{array}$ & 55 & \\
\hline Disease burden & 1 & 84.62 \\
\hline Loss of work & 9 & 1.54 \\
\hline Normal life & 65 & 13.85 \\
\hline Total & 100 \\
\hline
\end{tabular}

Likert scale on Families perceived outcome of Prostate Cancer diagnosis Families tended to agree that they had accepted their relative's prostate cancer diagnosis, they also felt that prostate cancer patients can live normally after treatment (table 13). On a five-point Likert scale the means were $4.12,3.43$ respectively and a median of 4 . Relatives seemed to disagree with the statement that prostate cancer patients were doomed to die and also that persons with prostate cancer could have intimate relationships. They were also not sure if they were embarrassed of their prostate cancer relative, prostate cancer affected intimacy between couples, It was shameful to have a prostate cancer relative, Prostate cancer patient could work effectively and whether prostate cancer is a serious disease (Table 13).

Table 13: Familyes opinion on prostate cancer diagnosis

\begin{tabular}{lllllllllll}
\hline Statement & SA & A & NS & D & SD & Med & Ave & Stdev & Mode \\
\hline $\begin{array}{l}\text { Family had accepted that a } \\
\text { relative had PCa }\end{array}$ & 29 & 23 & 5 & 8 & 1 & 4 & 4.12 & 1.01 & 5 \\
$\begin{array}{l}\text { Family was embarrassed of PCa } \\
\text { relative }\end{array}$ & 9 & 16 & 18 & 10 & 12 & 3 & 3 & 1.31 & 3 \\
\hline Prostate cancer affected & 14 & 9 & 10 & 22 & 9 & 3 & 2.95 & 1.4 & 2 \\
\hline
\end{tabular}


Journal Of Nursing Practice

http://thejnp.org

ISSN: 2614-3488 (print); 2614-3496 (online)

Vol.4 No.2. April 2021. Page.154-166

\begin{tabular}{l} 
intimacy between couples \\
\hline $\begin{array}{l}\text { It was shameful to have a PCa } \\
\text { relative }\end{array}$
\end{tabular}

\section{DISCUSSION}

Married patients had significantly longer median survival than those who were divorced, single, separated or widowed (Konrad et al., 1996). Konrad et al., (1996) further found out that in models that controlled for age, stage, race and treatment, married patients had a significantly lower risk of mortality than those who were divorced, single, separated or widowed. Occupation was found to have no association with the risk of having prostate cancer in a study which investigated if occupation such as farming exposed individual to herbicides and pesticides had an effect on the risk of having prostate cancer (Checkoway et al., 1986). The study by Bennett et al., (1998) recommended that low-literacy educational materials may improve patient awareness of prostate cancer and improve the frequency of diagnosis of early-stage cancer. In a study that investigated whether religion had an effect on the prostate cancer patients, the results revealed that relationship with God was a significant factor in the prediction of role, emotional and social functioning for these men after controlling for age, reported severity of treatment reactions and nonreligious resources (Gall, 2004). Results from this study also revealed that age group of 60-70 is most prone to prostate cancer as compared to age groups below 50 years and age groups above 90 years. These results concur with a research by Vickers et al., (2014) which revealed the age of 60 years as the one mostly prone to positive diagnosis of prostate cancer. Further research has shown that age is the greatest predisposing factor to the cancer of prostate (Loeb et al., 2006). The risk increases notably after fifty years in white populations and those with familial predisposition. The results show that the average age of prostate cancer patients is 69.76 years with a $95 \%$ confidence interval; had an average number of 5 children and average weight, height and BMI of $63.3 \mathrm{~kg}, 169.11 \mathrm{~cm}$ and 22.29 respectively.

The majority of the prostate cancer patients in this study had a body mass index of between $(20-25) \mathrm{kg} / \mathrm{m} 2$. The BMI indices are classified as; healthy (18.5-24.9), overweight (25-29.9) and obese $(\geq 30)$ (MacInnis et al, 2006). These findings show that majority of the patients were healthy though there was a significant number of them who were overweight and a very small percentage that was obese. Lepore et al., (2003) found out that education increased knowledge on prostate cancer. Further, it was found that individuals who scan or seek cancer information are those who acquire knowledge, adopt healthy lifestyle behaviours, and get screened for cancer (Shim et al., 2006). A study on knowledge, attitudes, and perception of prostate cancer among male outpatients of a tertiary care hospital in southeast Nigeria found out that there was a strong evidence of association between education and perception of prostate cancer (Aluh et al., 2018). Education was found to have an impact 
on knowledge since respondents with a middle school or lower and high school were less knowledgeable compared to those with a college degree or higher (Morlando et al., 2017).

A study by Ago et al (2001) in USA revealed that knowledge about prostate cancer was negatively correlated with age, education and income. The study further recommended a culturally sensitive promotional campaigns to increase awareness of the racial disparities in the incidence of prostate cancer and mortality rates. The statistics in this study portray a good health seeking behaviour following the diagnosis of prostate cancer. In a study by Pradhan et al., (2018), most of the study subjects were diagnosed at stage II and III. Diagnosis of cancer at advanced stages was attributed to the fact that there was inadequate awareness and inappropriate health seeking behaviour among general population. Most prostate cancer patients were observed to seek sexual medications (Hyde et al., 2016). This was attributed to masculine beliefs which are highly salient.

Men who were more emotionally self- reliant and attributed greater importance to sex formed stronger help-seeking intentions (Hyde et al., 2016). A study on health seeking behaviour among cancer patients attending ocean road cancer institute in Tanzania showed that $68.2 \%$ of the patients presented themselves when PCa was already at late stages of development (Kombe et al., 2007). Men were observed to have a poor health seeking behaviour after diagnosis with prostate cancer according to Hyde et al., (2017). This is because they felt that their masculinity had been eroded after being diagnosed with prostate cancer. For that reason, they were unwilling to go and seek health care provider's help since there is the traditional perception that men are never weak. The findings from this study contradict with the findings in a study in the United Kingdom which found that patient's and family's were dissatisfied with the current follow-up care regimes and information they were receiving (Lamers et al., 2016)

\section{CONCLUSION}

In conclusion, prostate cancer affects male population over certain age with higher prevalence. Since prostate cancer is a treatable disease if diagnosed early, individuals, and community should increase their levels of awareness, and knowledge. Patients and families perceived the diagnosis of prostate cancer as a death sentence. They also had low level of knowledge about PCa. A strong correlation was demonstrated between family history and increased risk of PCa. However, it was demonstrated that family history of PCa did not increase levels of knowledge on the causes of PCa. The results in this study showed that the highest number of prostate cancer patients were the married people; more patients were in informal employment as compared to formal employment; most of the patients had attained both primary and secondary education; majority of the prostate cancer patients in this study were Christians and the percentage of the number of patients who had no prostate cancer history in their families was higher than the percentage of the of patients who had the disease history in the family. A high percentage of the families who were the caretakers of the prostate cancer patients were their wives which agrees with the statistics that a bigger percentage of the patients were married. The social-demographics of a patient and family play a vital role in determining when they seek care, if they can afford that care, what the possible outcomes are and whether they will seek care at all.

\section{CONFLICTS OF INTEREST}

The authors declare no conflict of interest regarding publication of this paper. 


\section{Journal Of Nursing Practice}

http://thejnp.org

ISSN: 2614-3488 (print); 2614-3496 (online)

Vol.4 No.2. April 2021. Page.154-166

\section{REFERENCES}

Aluh, D. O., Anyachebelu, O. C., Azubuike, E. A., \& Abdulmuminu, I. (2018). Knowledge, attitudes, and perception of prostate cancer among male outpatients of a tertiary care hospital in south-east Nigeria. Journal of Applied Pharmaceutical Science, 8(11), 064-068. https://doi.org/10.7324/JAPS.2018.81109

Bennett, C. L., Ferreira, M. R., Davis, T. C., Kaplan, J., Weinberger, M., Kuzel, T., \& Sartor, O. (1998). Relation between literacy, race, and stage of presentation among low-income patients with prostate cancer. Journal of Clinical Oncology, 16(9), 3101-3104. https://doi.org/10.1200/JC0.1998.16.9.3101.

Calys-Tagoe, B. N. L., Yarney, J., Kenu, E., Adwoa, N., Amanhyia, K. O., Enchill, E., \& Obeng, I. (2014). Profile of cancer patients "seen at Korle BuTeaching Hospital in Ghana: A cancer registry review. BMC Cancer, 7(1), 1-6. https://doi.org/10.1186/1756-0500-7-577.

Checkoway, H., Diferdinando, G., Hulka, B. S., \& Mickey, D. D. (1987). Medical, life-style, and occupational risk factors for prostate cancer. The Prostate, 10(1), 79-88. https://doi.org/10.1002/pros.2990100111

Etawo, U. S., Ekeke, N. O., \& Mbiaba, A. B. (2012). Prospective study of sex hormone levels among prostate cancer patients attending the University of Port Harcourt Teaching Hospital clinic. The Nigerian Health Journal, 12(2), 39-42. https://www.ajol.info/index.php/nhj/article/view/81256.

Gall, T. L. (2004). Relationship with God and the quality of life of prostate cancer survivors. Quality of Life Research, 13(8), 1357-1368. https://doi.org/10.1023/B:QURE.0000040789.49691.59

Hyde, M. K., Zajdlewicz, L., Wootten, A. C., Nelson, C. J., Lowe, A., Dunn, J., \& Chambers, S. K. (2016). Medical help-seeking for sexual concerns in prostate cancer survivors. Sexual medicine, 4(1), e7-e17. https://doi.org/10.1016/j.esxm.2015.12.004.

Jemal, A., Lortet-tieulent, J., Ward, E., Ferlay, J., Brawley, O., \& Bray, F. (2012). International variation in prostate cancer incidenc and mortalit rates. European Urology, 61, 1079-1092. https://doi.org/10.1016/j.eururo.2012.02.054

Kombe, D., Yuma, S., Mtiro, H., \& Mlawa, G. (2007). Health seeking behavior among cancer patients attending Ocean Road Cancer Institute, Tanzania. East African journal of public health, 4(1), 19-22. https://pubmed.ncbi.nlm.nih.gov/17907756/

Konrad, A., Lai, H., Burke, M. A., Goodkin, K., \& Lai, S. (1996). Marriage and mortality in prostate cancer. The Journal of urology, 156(5), 1696-1700. https://doi.org/10.1016/S0022-5347(01)65485-5

Lamers, R. E., Cuypers, M., \& Husson, O. (2016). Patients are dissatisfied with information provision: perceived information provision and quality of life in prostate cancer patients. Psychooncology 2016;25: 633-40. https://doi.org/10.1002/pon.3981. 


\section{Journal Of Nursing Practice}

http://thejnp.org

ISSN: 2614-3488 (print); 2614-3496 (online)

Vol.4 No.2. April 2021. Page.154-166

Lepore, S. J., Helgeson, V. S., Eton, D. T., \& Schulz, R. (2003). Improving quality of life in men with prostate cancer: a randomized controlled trial of group education interventions. Health Psychology: Official Journal of the Division of Health Psychology, American Psychological Association, 22(5), 443-452. https: //doi.org/10.1037/0278-6133.22.5.443

Loeb, S., Roehl, K. A., Antenor, J. A. V., Catalona, W. J., Suarez, B. K., \& Nadler, R. B. (2006). Baseline prostate-specific antigen compared with median prostate-specific antigen for age group as predictor of prostate cancer risk in men younger than 60 years old. Urology, 67(2), 316-320. https://doi.org/10.1016/j.urology.2005.08.040

MacInnis, R. J., \& English, D. R. (2006). Body size and composition and prostate cancer risk: systematic review and meta-regression analysis. Cancer causes \& control, 17(8), 989-1003. https://doi.org/10.1007/s10552-006-0049-z.

Morlando, M., Pelullo, C. P., \& Di Giuseppe, G. (2017). Prostate cancer screening: Knowledge, attitudes and practices in a sample of men in Italy. A survey. PloS one, 12(10), e0186332. 7 https://doi.org/10.1371/journal.pone.0186332

Pradhan, S. K., Gupta, S. A., Shrivastava, N., Verma, N., Dixit, S., \& Panda, P. S. (2018). Health seeking behaviour and factors affecting it among oral cancer patients seeking radiotherapy at a regional cancer centre: a retrospective study. International Journal Of Community Medicine And Public Health, 5(4), 1647 1652. https://doi.org/10.18203/2394-6040.ijcmph20181250

Rebbeck, T. R., Zeigler-Johnson, C. M., Heyns, C. F., \& Gueye, S. M. (2011). Prostate cancer screening, detection and treatment practices among sub- Shara African urologists. Africa Journal of Urologist, 17(3), 55-91. https://doi.org/10.1007/s12301-011-0016-0

Roth, A. J., Weinberger, M. I., \& Nelson, C. J. (2008). Prostate cancer: psychosocial implications and management. Future Oncology, 4(4), 561-568. https://doi.org/10.2217/14796694.4.4.561

Shim, M., Kelly, B., \& Hornik, R. (2006). Cancer information scanning and seeking behavior is associated with knowledge, lifestyle choices, and screening. Journal of Health Communication, 11(S1), 157-172. https://doi.org/10.1080/10810730600637475

Vickers, A. J., Ulmert, D., Sjoberg, D. D., Bennette, C. J., Björk, T., Gerdtsson, A., \& Scardino, P. T. (2013). Strategy for detection of prostate cancer based on relation between prostate specific antigen at ag e 40-55 and long term risk of metastasis: case-control study. Bmj, 346, f2023. https://doi.org/10.1136/bmi.f2023.

Wolf, A. M. D. (2013). Prostate cancer treatment choices. Annals of Internal Medicine. https://doi.org/10.7326/0003-4819-159-6-201309170-00018 